Knights, B. A. \& Laurie, W. (1967). Phytochemistry, 6, 407.

Lederer, E. (1964). Biochem. J. 98, 449.

Mauthner, J. \& Suida, W. (1903). Mh. Chem. 24, 648.

Paliokas, A. M. \& Schroepfer, G. J. (1968). J. biol. Chem. 248, 453.

Patterson, G. W. \& Karlander, E. P. (1967). Plant Physiol. 42, 1651.

Popják, G. \& Cornforth, J. W. (1966). Biochem.J. 101, 553.

Rees, H. H., Goad, L. J. \& Goodwin, T. W. (1968). Biochem. $J .107,417$.

Richards, J. H. \& Hendrickson, J. B. (1964). The Biosynthesis of Steroids, Terpenes and Acetogenins, p. 274. New York: W. A. Benjamin Co.

Ruzicka, L. (1959). Proc. chem. Soc., Lond., p. 341.

Samuelsson, B. \& Goodman, D. S. (1963). J. biol. Chem. 239, 98.
Schwenk, E. \& Werthessen, N. T. (1952). Arch. Biochem. Biophys. 40, 334.

Smith, A. R. H., Goad, L. J. \& Goodwin, T. W. (1968). Chem. Commun. p. 926.

Smith, A. R. H., Goad, L. J., Goodwin, T. W. \& Lederer, E. (1967). Biochem.J. 104, 566.

Tsuda, K., Akagi, S., Kishida, Y., Hayatsu, R. \& Sakai, K. (1958). Chem. Pharm. Bull., Tokyo, 6, 724.

van Aller, R. T., Chikamatsu, H., de Souza, N. J., John, J. P. \& Nes, W. R. (1968). Biochem. biophys. Res. Commun. 31, 842.

Williams, B. L., Goad, L. J. \& Goodwin, T. W. (1967). Phytochemistry, 6, 1137.

Williams, R. J. H., Britton, G., Charlton, J. M. \& Goodwin, T. W. (1967). Biochem. J. 104, 767.

Wilton, D. C., Munday, K. A., Skinner, S. J. M. \& Akhtar, M. (1968). Biochem. J. 106, 803.

\title{
ADDENDUM
}

\section{Incorporation of $\left[2-{ }^{14} \mathrm{C}\right]$ Mevalonic Acid into 28 -Isofucosterol by Leaves of Pisum sativum}

\author{
BY LORETTA M. BOLGER, H. H. REES, L. J. GOAD AND T. W. GOODWIN \\ Department of Biochemistry, University of Liverpool, L69 3BX
}

(Received 2 June 1969)

During a previous examination of the sterols of pea (Pisum sativum) leaves we noted a minor component that was tentatively identified as fucosterol on the basis of g.l.c. retention results (Goad \& Goodwin, 1966). However, the isomer of fucosterol, 28-isofucosterol, has since been identified as a minor constituent of oat seeds and a few other plants (Knights, 1965; B. H. Knights, personal communication). It therefore became of interest for us to reinvestigate the pea leaf sterol, and the availability of a sample of 28-isofucosterol (Gibbons, Goad \& Goodwin, 1968) made this possible. Comparison of the g.l.c. retention times of fucosterol and 28-isofucosterol on the stationary phase cyclohexane dimethanol succinate (CHDMS, also known as Hi-EFF-8B) showed that they can be distinguished when they constitute the major component, as described by Knights (1965). However, when these sterols comprised only a small percentage of the total sterol mixture, as was the case in the pea leaf sterols (Goad \& Goodwin, 1966), it was difficult on our column to differentiate between the two components with certainty. We therefore resorted to radiochemical methods to confirm the presence of 28-isofucosterol in pea leaves.

\section{EXPERIMENTAL AND RESULTS}

Methods were generally as described previously (Goad \& Goodwin, 1966; Williams, Goad \&
Goodwin, 1967; Goad, Gibbons, Bolger, Rees \& Goodwin, 1969). Peas (variety Onward) were germinated for 7 days and $3.0 \mathrm{~g}$. of the freshly developed leaves chopped into strips and moistened with $1.0 \mathrm{ml}$. of a solution of $\left[2-{ }^{14} \mathrm{C}\right] \mathrm{mevalonic}$ acid $(5 \cdot 0 \mu \mathrm{c})$. After $6 \mathrm{hr}$. incubation at $25^{\circ}$ with illumination, the non-saponifiable lipids (10.0 mg.; $8.0 \times$ $10^{5}$ c.p.m.) were extracted in the usual manner. Preparative t.l.c. on silica gel developed with chloroform gave the 4-demethyl sterol fraction (2.0mg.; $1.9 \times 10^{5}$ c.p.m.). To this material 28isofucosterol ( $1.0 \mathrm{mg}$.) was added, the mixture was subjected to t.l.c. on $10 \%$ silver nitrate-impregnated silica gel developed with chloroform, and the

Table 1. Crystallization of the labelled 24-ethylidene sterol of pea leaves with 28-isofucosterol or fucosterol

Sp. radioactivity (c.p.m./mg.)

$\begin{array}{ccc}\text { Crystallization no. } & \text { 28-Isofucosterol } & \text { Fucosterol } \\ 1 & 245 & 256 \\ 2 & 199 & 188 \\ 3 & 226 & 137 \\ 4 & 214 & 90 \\ 5 & 204 & 90 \\ 6 & 177 & 77 \\ 7 & 174 & 67 \\ 8 & 207 & 28\end{array}$


$\beta$-sitosterol (3.27 $\times 10^{4}$ c.p.m.) and 28-isofucosterol $\left(3.14 \times 10^{4}\right.$ c.p.m.) bands were eluted. In addition, marker spots of $\alpha$-spinasterol and ergosterol were run on the plate and the bands corresponding to the $\Delta^{7}$ sterol $\left(1.43 \times 10^{4}\right.$ c.p.m. $)$ and the $\Delta^{5,7}$ sterol $\left(1.36 \times 10^{4}\right.$ c.p.m.) were also eluted but were not further characterized. Equal portions $(5 \cdot 23 \times$ $10^{3}$ c.p.m.) of the material co-chromatographing with 28-isofucosterol were added to carrier 28-isofucosterol (20.1 mg.) or fucosterol (19.7 mg.) and the mixtures crystallized several times (Table 1). Crystallization with 28-isofucosterol resulted in essentially constant specific radioactivity after the first crystallization; however, with fucosterol as carrier there was a continual decrease in specific radioactivity until a very low value was reached, at which point insufficient material prevented further crystallization.

\section{DISCUSSION}

The above results establish that the 24-ethylidene sterol of pea leaves, into which [2-14C]mevalonic acid is readily incorporated, is 28-isofucosterol and not fucosterol as earlier suggested. This is in accord with the results obtained with leaves of Larix decidua (Goad et al. 1969).

\section{REFERENCES}

Gibbons, G. F., Goad, L. J. \& Goodwin, T. W. (1968). Phytochemistry, 7, 983.

Goad, L. J., Gibbons, G. E., Bolger, L., Rees, H. H. \& Goodwin, T. W. (1969). Biochem. J. 114, 885.

Goad, L. J. \& Goodwin, T. W. (1966). Biochem. J. 99, 735.

Knights, B. H. (1965). Phytochemistry, 4, 857.

Williams, B. L., Goad, L. J. \& Goodwin, T. W. (1967). Phytochemistry, 6, 1137. 